\title{
Mass Transfer Coefficient Study for Release of Naproxen from Activated Carbon for Drug Delivery application
}

\author{
Shahad F. Hameed ${ }^{a}$, Salih A. Rushdi ${ }^{{ }^{*}}$ \\ ${ }^{a}$ Department of chemical engineering, University of Al-Qadisiyah, Al-Qadisiyah, Iraq.
}

\author{
A R T I CLE INFO \\ Article history: \\ Received 00 December 2019 \\ Accepted 00 February 2019

\section{Keywords:} \\ Activated Carbon \\ Drug delivery \\ Loading \\ Mass Transfer Coefficient \\ Naproxen \\ Release
}

Received in revised form 00 January 2019

\begin{abstract}
A B S T R AC T
Activated carbon is a porous material that has a great character to be used for drug delivery system as a carrier. It is agreed that drug carriers maintain the concentration of drugs within the required range for a long period and undetermined toxicity resulting from the use of overdoses. They have the ability to direct the drug to the affected area, immunity, biophysics, and drug efficacy. Activated carbon was used at two different particle sizes $(0.6 \mu \mathrm{m}$ size with surface area $544.4704 \mathrm{~m} 2 / \mathrm{g}$ and $11.042 \mathrm{~nm}$ size with surface area $985.6013 \mathrm{~m} 2 / \mathrm{g})$ and Naproxen was used as a drug model. This research studied the effect of several parameters, including particle size $(11.042 \mathrm{~nm}$ and $0.6 \mu \mathrm{m})$, weight of drug to carrier weight ratio $(0.5,1$ and $1.5)$ on loading efficiency, and temperature $\left(35,37\right.$ and $\left.39^{\circ} \mathrm{C}\right)$, time $(1,3$ and $5 \mathrm{hr})$, $\mathrm{pH}$ of the solution $(1.5$ and 6.5) on mass transfer coefficient in release drug. The result of experiments showed that maximum loading efficiency can be obtained when the particle size of activated carbon was in Nano-size and the ratio of drug weight to AC weight was 1.5. The release process was studied by studying the mass transfer coefficient, the highest value of the mass transfer coefficient was obtained at the beginning of the unloading time, at temperature $37^{\circ} \mathrm{C}$ and solution in $\mathrm{pH} 6.5$.
\end{abstract}

\section{Introduction}

In recent years, new ideas have been developed on pharmacokinetics control, pharmacodynamics, undetermined toxicity, immunity, biophysics, and drug efficiency. A smart drug delivery system (SDDS) was the name of these strategies [1]. Because of the development of new pharmaceutical molecules is costly and time-consuming, one alternative is to increase the effectiveness of older drugs by delivering them at a controlled rate and effectively targeting them. This strategy consists of transferring a specified amount of therapeutic agent for an extended period to a specific area in the body at a controlled manner [2], which symbolizes one of the key areas developed rapidly in the sciences in which chemical engineers and chemists contribute to the care of human health. It is one of the main objectives of the science of pharmacy, drug activity is endemic in the workplace and is

\footnotetext{
* Corresponding author.

E-mail address: dr.alsalih@gmail.com ( Salih Al Shemry)
} 


\begin{tabular}{|lllll|}
\hline \multicolumn{2}{l}{ Nomenclature } & & & \\
AC & Activated Carbon & & \\
CN & Carbon nanotubes & SDDS & smart drug delivery systems \\
DF & Degree of freedom & Seq ss & The sequential sum of squares \\
eff. & efficiency & UV & Ultraviolet-visible \\
EPR & Enhanced Permeability and Retention & W & Weight \\
G & grams & SN & Signal to Noise ratios \\
$\mathrm{Hr}$ & hour & CSat & saturation drug concentration at the solid surface of particle \\
IBU & ibuprofen & D & diffusion \\
macro. & Macro particle size & J & Molar flux rate of drug \\
ml & Milliliter & K & overall mass transfer coefficient \\
Nano. & Nanoparticle size & t & time \\
PA & paracetamol & A & area of particle \\
PSi & Porous silicon & C & concentration of drug at the edge of the fluid diffusion layer \\
& & & in the bulk solution \\
CN & Carbon nanotubes & & \\
\hline
\end{tabular}

necessary for improving the treatment of diseases [3], through selective accumulation in situ and less accumulation elsewhere, hence increasing the therapeutic value of the drug and reduce drug costs and take advantage of current treatment methods at a lower price. They also include less toxicity, enhanced efficacy [4], patient comfort, and compliance than conventional doses in addition to the possibility of using the medicine currently available $[5]$.

The process of loading can be achieved through several steps, one of them is the principle of adsorption, which is defined as the collection of substances (usually ions or gases in the form of atoms or molecules) called absorbents materials on the surface of other porous solids material called adsorbents materials.

Adsorption occurs as a result of an imbalance of the molecular forces of the surfaces of liquids and solids, and there are two types of adsorption, physical and chemical [6]. Here the loading process depends on physical adsorption (van der Waals adsorption). The working force between the surfaces adsorbent and absorbed is the forces of van der Waals, which are natural forces of attraction between the adsorbent, which is idle due to the electronic saturation of its atoms due to the bonds with which these atoms are connecting with ions or the molecules that adsorbed on the surface of atoms adjacent to the substance itself [7]. Loading efficiency of drugs calculate by using this equation [15].

loading eff. $=\frac{\text { weight of the drug in a complex }}{\text { total weight of complex }}$

The change in drug concentration over time is reliant upon three factors: the diffusion of the drug into or out of the system, the amount of drug leaving or entering the system due to bulk fluid flow and the generation or consumption of the drug within the system [8]. The diffusion of a drug is proportional to the concentration gradient. When there is a steep concentration gradient, such as when a drug delivery vehicle is placing in a fluid containing no drug, the diffusion occurs faster than when the concentration gradient is low, such as when the concentration outside of a delivery vehicle is near the concentration inside the delivery vehicle [1]. When the concentrations in one area are equal to concentrations in an adjacent area, there will be no diffusive exchange of the molecule between those areas. Diffusion is also a function of a physical constant, the diffusion coefficient, that describes the inherent properties of the material a molecule is diffusing through in a dense material, such as bone, the diffusion coefficient of a molecule is lower than in a free liquid such as water. Diffusion coefficients are related, among other factors, to the size of the molecule diffusing. Large molecules will diffuse more slowly, have a lower diffusion coefficient, than smaller molecules [9].

Solubility is the maximum quantity of a solute drug that can be dissolved in the solvent, while the solubility rate (dissolution) is the rate at which this solute dissolves in the solvent. According to Brunner and Nernst equation the disintegration of the drug in a medium is influencing by several factors such as solubility, wettability of the drug, the absorption conditions of the dissolved medium and the surface area of the drug [10, 13]. Several strategies have been developed to modify the above factors to improve the solubility or solubility rate of drugs with poor water solubility; however, such techniques are often relating to limitations concerning poor stability and low drug loading. One of the many soluble enhancing techniques involves converting the crystalline drug into an amorphous state, because the rate of decomposition of the amorphous form is significantly better than the crystalline form, especially in high energy crystalline drugs [14]. The dissolution of solid drug suspended in solution is known to be controlled by the diffusion of this drug away from the solid surface of the undissolved material.

Starting with a mass balance equation to associate the dissolution result with a mass transfer coefficient then integrating it with boundary condition $\mathrm{C}=0$ at $\mathrm{t}=0$

accumulation of drug in solution = total dissolution rate

$V \frac{d c}{d t}=A j$

$j=A K\left(c_{\text {sat }}-c\right)$

Sup eq (3)in (2)

$V \frac{d c}{d t}=A K\left(c_{s a t}-c\right)$

Rearrangement eq (4)

$\frac{d c}{c_{s a t}-c}=\frac{A K}{V} d t$

Integrate eq (5) with boundary condition $\mathrm{c}=0$ at $\mathrm{t}=0$

$-\ln \left(c_{\text {sat }}-c\right)=\frac{A K}{V} t+B$

Compensating B.C. where B is integration constant

$B=-\ln c_{\text {sat }}$

Sub in eq (6)

$\ln \frac{c_{\text {sat }}}{c_{\text {sat }}-c}=\frac{A K}{V} t \quad$ or $\quad \frac{c}{c_{\text {sat }}}=1-\exp \left(-\frac{A K}{V} t\right)$

$\therefore K=\frac{V}{A t} \ln \frac{c_{s a t}}{c_{s a t}-c}$ 
Many previous studies have been used carbon as a drug carrier. Activated carbon(AC) was used as a drug carrier while PA and IBU were used as drugs that were loaded into AC at $44.4 \%$ and $20.7 \%$ loading efficiency respectively. Related studies suggested that within $10 \mathrm{~min}$ drug release for two $\mathrm{PA} / \mathrm{AC}$ and IBU/AC complexes was completed in the presence of sodium phosphate buffer $(\mathrm{pH}$ 5.8) [15]. AC is using in drug delivery research because of its high internal volume, its ability to cross the cell, membrane easily, small size, surface area increases to volume ratio, and its capability to include chemicals and high drug loading, among other types that making it's helpful for cancer treatment [16]. Cancer is one of the most difficult diseases of new times because its treatment includes distinguishing infected cells from normal healthy cells. Here, Carbon nanotubes $(\mathrm{CN})$ plays a vital role because of a phenomena such as EPR which leading $\mathrm{CN}$ types to distinguish normal cells from infected cells, the major advantage in cancer treatment [17], hence helping in developing an effective, inexpensive, and safe delivery of oral medication, therefore, carbon materials were used in biomedical applications for several decades [16]. AC is a space surrounded by carbon atoms, having other names like active carbon, activated charcoal, or activated coal. This space (porous) has zero electron density and possesses intense van der Waals forces, which are responsible for its exceptional ability to adsorb chemical species. These forces depend on the distance between carbon atoms and the bond arrangement of bonds between carbon and hetero-atoms [17]. One of the first applications is the use of activated carbon to build synthetic heart valves and in blood, embolisms to treat external and internal poisoning with different causes. Applications of new carbon nanotubes depend on their mechanical, physical, structural, and chemical characteristics, which are often superior to other materials. This benefit is propped by the truth that many carbon materials have perfect biological compatibility and could utilize in direct connection with human blood and tissues. The biological compatibility phenomenon is too complex, and its main factors are not yet fully comprehended, yet it is called to be related to protein absorption on the surface of materials exposed to the human body [18]. Mesoporous silicon microparticles (PSi) were used as a pharmaceutical carrier, these Mesoporous silicon particles produced by using thermal oxidation or thermal carbonization to obtain suitable surfaces for the ability to administer the oral drug. Five typical drugs ibuprofen, ranitidine, furosemide, griseofulvin, and antipyrine were used. The loading efficiency obtained was between $9 \%$ and $45 \%$ with (Psi) Mesoporous silicon molecules, in addition to the effects related to the stability of the particles in the presence of organic or aqueous solvents. The properties of the surface, loading solution and the chemical nature of the drug are found to be critical to the loading process. The release rate of drug-loaded from particles of PSi depends on the properties and solubility behavior of the drug materials. When the rate of drug dissolution (unloading drug) was high, microscopic particles caused the release delay. However, with poor drug dissolution, loading into microscopic particles improves solubility. In addition, the $\mathrm{pH}$ dependency of the dissolving process decreased when the substance of the drug-loaded into microscopic particles [19]. The main objective of this work is to obtain more release naproxen control by loading naproxen on carbon molecules and study the change of loading efficiency with the change of the size and quantity of activated carbon carrier relative to the amount of the drug. In addition, the effect of the mentioned later factors on the release process was studied through the mass transfer coefficient.

\section{Materials and Experimental Procedure}

\subsection{Materials}

- Two types of activated carbon with different particles size were used, the first was Macro particle size $0.6 \mu$ with surface area $544.4704 \mathrm{~m}^{2} / \mathrm{g}$ purchased from Sigma Aldrich and the second was Nanoparticle size $11.042 \mathrm{~nm}$ with surface area $985.6013 \mathrm{~m}^{2} / \mathrm{g}$ purchased from lab shop.

- Naproxen from Cayman company.

- Ethanol alcohol $\mathrm{C}_{2} \mathrm{H}_{5} \mathrm{OH}$ (purity 99.9\%) with density $789\left(\mathrm{~kg} / \mathrm{m}^{3}\right)$.

- Methanol alcohol $\mathrm{CH}_{3} \mathrm{OH}$ (purity $99 \%$ )with density $792\left(\mathrm{~kg} / \mathrm{m}^{3}\right)$.

- Hydrochloric acid $\mathrm{HCl}$ with normality of $11.5 \mathrm{~N}$ (mole/l).

- Injection water $100 \%$ of Sterile water for injection from a local source.

- Silica Gel from a local source.

\subsection{Experimental Procedure}

\subsection{1. loading drug Stage}

Sample of drug/AC was prepared by dissolve naproxen in ethanol according to saturation solubility $100 \mathrm{mg} / \mathrm{ml}$. then $5 \mathrm{~g}$ activated carbon was added to the naproxen ethanol solution as shown in Table 1. the solution was mixed by a magnetic stirrer for 24 hours at room temperature then the solution was subjected to an initial drying by Buchner funnel, here the material was weighed, and the volume of the remaining liquid was measured. Dry the remaining material in an oven for 4 hours at a temperature of 40-degree centigrade, and the samples were weighed. Finally the substance kept in sealed cans inside a container containing silica gel.

The concentration of drugs in the solution on the Buchner funnel was measured by UV spectrometer. This concentration will be multiplied by the volume of the solution to determine the weight of the unloaded drug [15]. loading efficiency calculated by use eq (1)

\subsubsection{Calculation the Mass Transfer Coefficient}

In this work, The experiments were designed by Taguchi (licensing 17.1.0 2013). Three factors were considered; temperature, $\mathrm{pH}$ of solution, and time. $\mathrm{pH}$ of solution was studied at two-levels (1.5 and 6.5),temperature at three-levels $\left(35,37\right.$ and $\left.39^{\circ} \mathrm{C}\right)$ and time at three-levels $(1,3,5 \mathrm{hr})$. The mass transfer coefficient was calculated by using eq (7) through 18 run number of experiments.

Mass transfer coefficient calculated depending on the concentration of drugs at different times to determine this concentration of complex by taking $100 \mathrm{ml}$ from two solutions $\mathrm{pH} 1.5$ prepared from 99\% Water injected and $1 \%$ hydrochloric acid and $\mathrm{pH} 6.5$ prepared from $99 \%$ Injection and $1 \%$ methanol) taken in 6 beakers then added (87.71) $\mathrm{mg}$ from the naproxen /macro AC sample and (84.74) $\mathrm{mg}$ from the naproxen/Nano AC sample to glasses these amount taken according to the standard dosage weights of $500 \mathrm{mg}$ for naproxen and loading eff. for macro and nano activated carbon. Then put the beakers in shaking water bath sate the temperature $(35,37,39) \mathrm{c}^{\mathrm{o}}$ and 50 shakings per minute[20], then calculate the concentration for 6 hour time by UV spectrometer. 


\section{3. Results and Discussions}

\subsection{Naproxen Loading Results}

Fig. 1. show that the loading efficiency slightly increased when the AC particle size decreases from macro to Nano-size at any W drug / W AC while a maximum loading efficiency was achieved at $1.5 / 1 \mathrm{~W}$ drug / W AC ratio for AC nanoparticle during the loading.

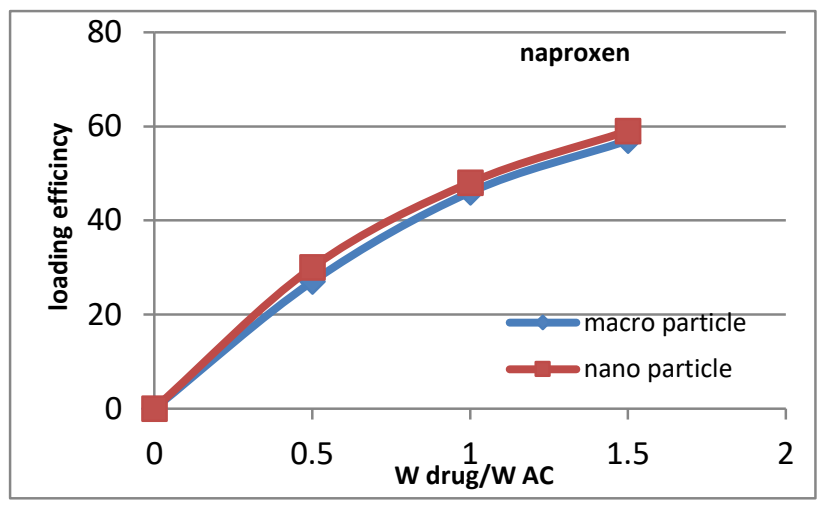

Figure 1. loading efficiency behaviour for naproxen drug

As shown in Table 1. there is little difference between the quantities produced and the actual quantities used. This difference was happened because of the adhesion of some of the mixture in the equipment used during the experiment, including the filter papers. Loading efficiency was reached a maximum of around 24 hours of incubation, after which the loading efficiency no longer increases and in some cases, is even lowered.

\subsection{Naproxen Unloading Results}

Naproxen release from the complex was incompleted due to the poor wettability of carbon particles which may increase or decrease the emission period leading to the stronger effect of AC porosity on Solubility profiles.

Fig. 2. shows that when $\mathrm{pH}=6.5$ and at 6 hours, $100 \%$ drug release occurred when the drug pure without carbon and $\sim 80 \%$ release from macro activated carbon while the best result ( $70 \%$ release ) was obtained from nano activated carbon and showed that the release was controlled at drug/nanoAC complex. When $\mathrm{pH}=1.5$, Fig. 3. shows that at 6 hours $\sim 100 \%$ drug release when the drug pure without carbon and $80 \%$ release from macro activated carbon while the best result release $>70 \%$ was obtained from Nano-activated carbon. The Comparative between these figures shows that at $\mathrm{pH} 6.5$ the drug release was more control.

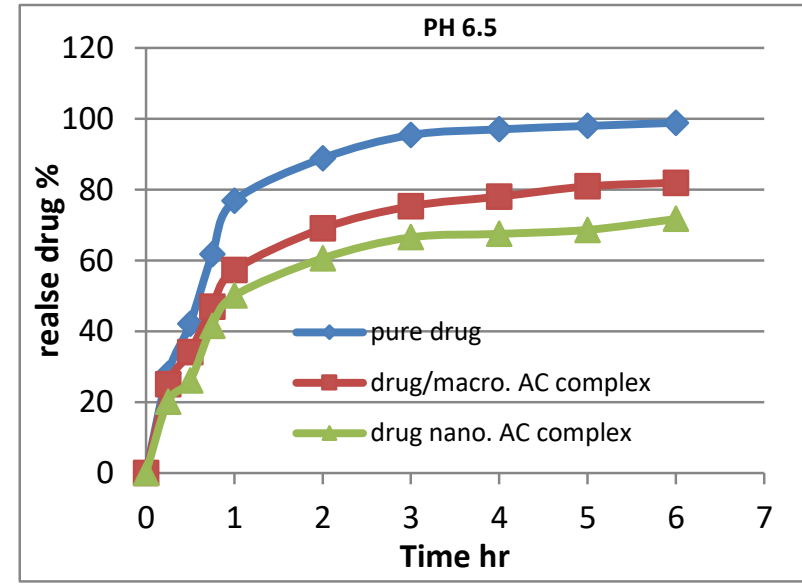

Figure 2. Naproxen release pattern in PH6.5 solutions

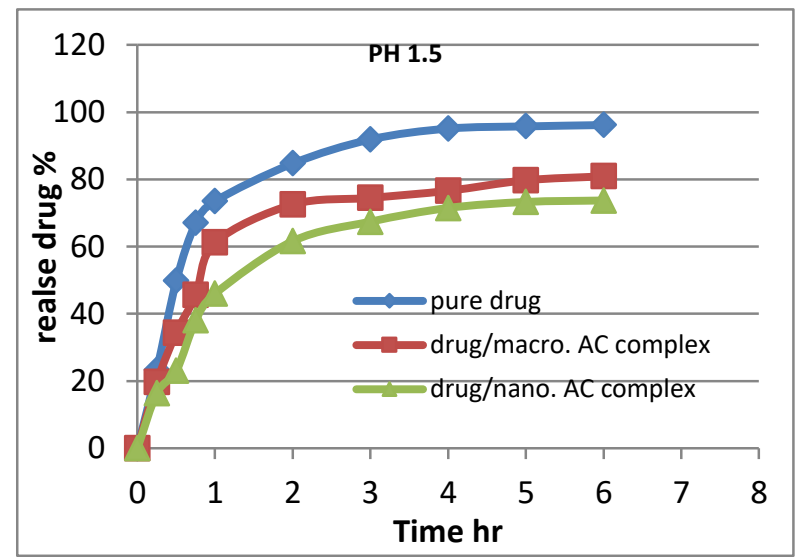

Figure 3. Naproxen release pattern in PH1.5 solutions

The mass transfer coefficient values were obtained from using Equation (3) that given the saturated concentrations of $0.5 \mathrm{mg} / \mathrm{ml}$ for naproxen. As shown in Figs. 4.7 there is some similarity in the Mass Transfer Coefficient Variation with Time and the coefficient increases in the dissolution medium from zero to the highest value and then begins to decline gradually until it reaches a stage that is controlled slightly less with time, this was due to the loading process.

Table 1. Drug Loading step result for naproxen loading

\begin{tabular}{|c|c|c|c|c|c|c|c|c|c|c|}
\hline Drugs & $\begin{array}{l}\text { Type } \\
\text { of AC }\end{array}$ & $\frac{W(\text { drug }) g m}{W(d r u g) g m}$ & $\begin{array}{l}\text { Vol. of } \\
\text { ethanol } \\
(\mathrm{ml})\end{array}$ & $\begin{array}{c}\text { W of } \\
\text { complex } \\
\text { before } \\
\text { dray }\end{array}$ & $\begin{array}{c}\text { W of } \\
\text { complex } \\
\text { after } \\
\text { dray }\end{array}$ & $\begin{array}{l}\text { Vol. of } \\
\text { sol. } \\
\text { Remain } \\
\text { (ml) }\end{array}$ & $\begin{array}{c}\text { Cons. } \\
\text { drug } \\
\left(\mathrm{g} / \mathrm{ml}_{2}\right) \times 10^{-}\end{array}$ & $\begin{array}{c}\text { W } \\
\text { drug } \\
\text { unload. } \\
(\mathrm{g})\end{array}$ & $\begin{array}{c}\text { W } \\
\text { drug } \\
\text { loading } \\
(\mathrm{g})\end{array}$ & Eff. $\%$ \\
\hline \multirow{6}{*}{ Naproxen } & \multirow{3}{*}{ Macro } & $2.5 / 5$ & 25 & 10.714 & 6.901 & 10 & 3.74 & 0.374 & 2.126 & 30 \\
\hline & & $5 / 5$ & 50 & 17.316 & 8.896 & 28 & 3.13 & 0.876 & 4.124 & 46 \\
\hline & & $7.5 / 5$ & 75 & 20.836 & 11.239 & 42 & 2.49 & 1.046 & 6.454 & 57 \\
\hline & \multirow{3}{*}{ Nano } & $2.5 / 5$ & 25 & 14.782 & 7.458 & 7 & 3.2 & 0.224 & 2.276 & 30 \\
\hline & & $5 / 5$ & 50 & 21.615 & 9.393 & 11 & 3.17 & 0.349 & 4.651 & 48 \\
\hline & & $7.5 / 5$ & 75 & 29.977 & 11.769 & 25 & 2.65 & 0.663 & 6.837 & 59 \\
\hline
\end{tabular}




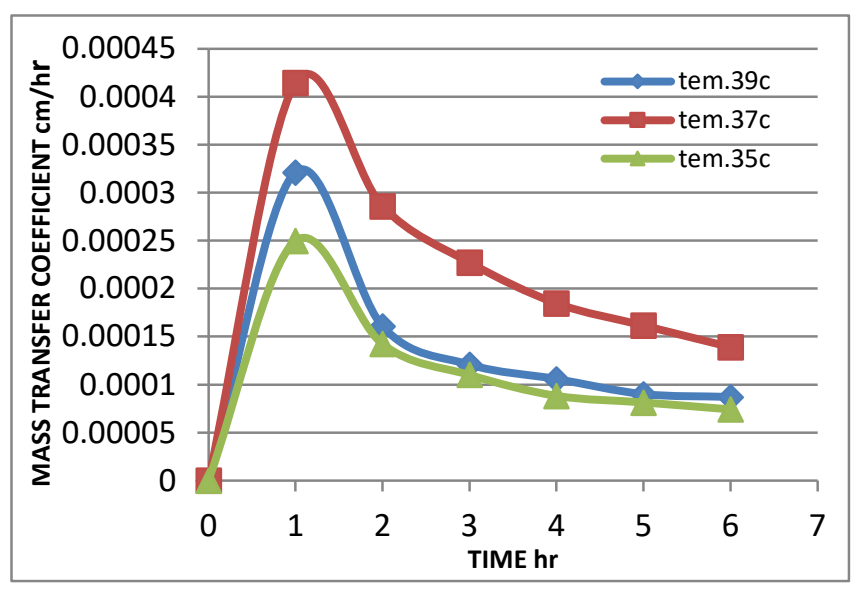

Figure 4. Mass transfer coefficient Variation with time for naproxen/macro AC sample in PH 6.5

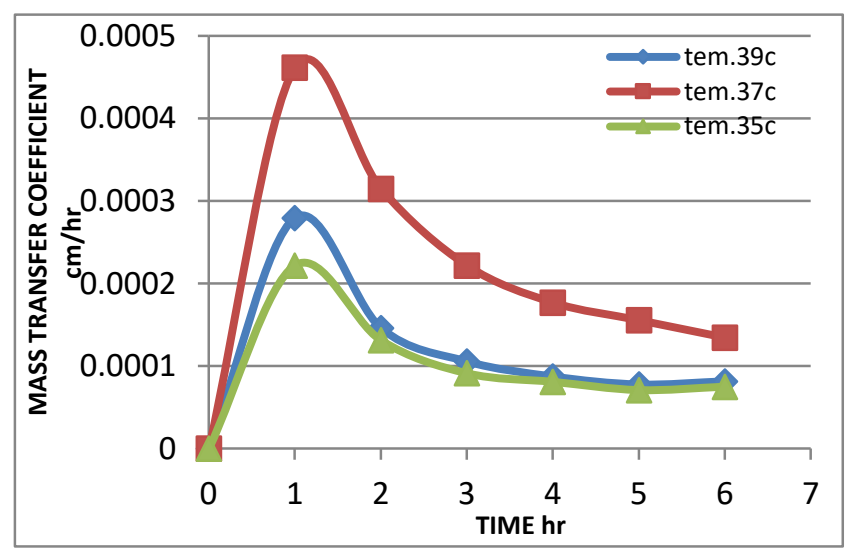

Figure 5. Mass transfer coefficient Variation with time for naproxen/macro AC sample in PH 1.5

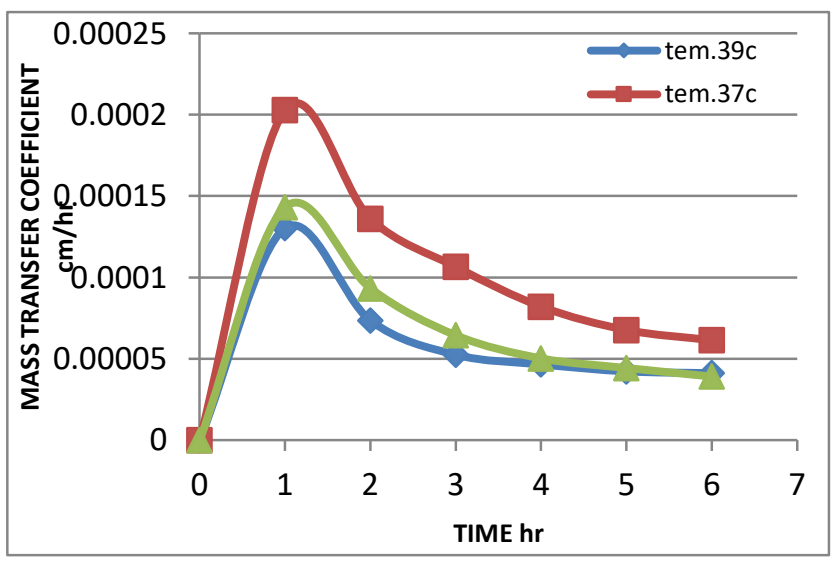

Figure 6. Mass transfer coefficient Variation with time for naproxen/Nano. AC sample in PH 6.5

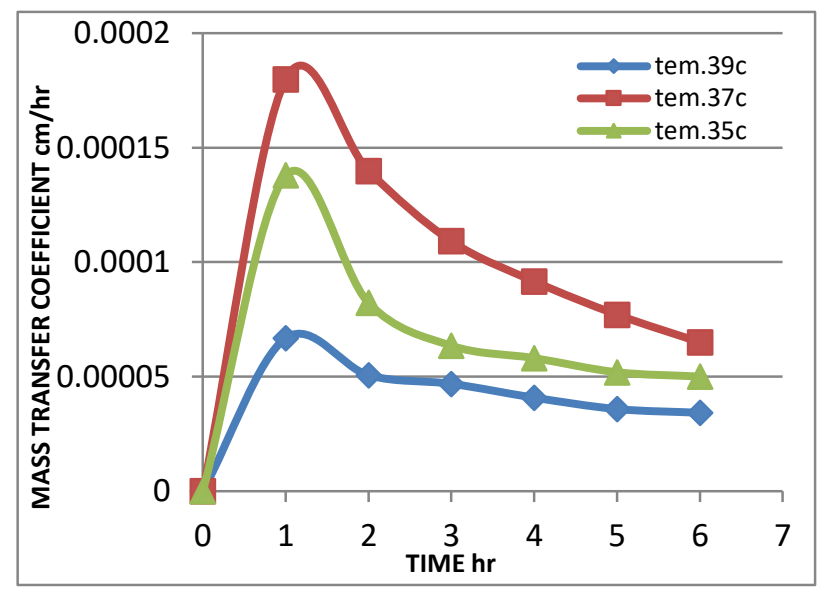

Figure 7. Mass transfer coefficient Variation with time for naproxen/Nano. AC sample in PH 1.5

The results of the statistical analysis using Taguchi program show the effect of the three variables on the mass transfer coefficient as follows:

-Naproxen/macro.AC complex, The most effective parameter was time with present of contribution (69.22\%), while the least effect is $\mathrm{pH}$ solution with present of contribution $(0.12 \%)$.

-Naproxen/nano.AC complex, The most effective parameter was time with present of contribution $(62.78 \%$ ), while the least effect is $\mathrm{pH}$ solution with present of contribution $(0.97 \%)$.

Note from the Table 2. that all coefficient for a factor is significant (R_sq value > 0.9), so could conclude that the relation between the response and a factor relies on the factors in the expression. The coefficient contribution explains the direction and size of the relation between the variable of response and factors in the model, so the relative strength of each factor represents the absolute value of this coefficient. The coefficient Minitab number determines for a factor was the level number minus one.

The Regression Equations for Mass Transfer Coefficient (Multiple Linear Regression Model) is given by:

$y=b 0+b 1 x 1 i+b 2 x 2 i+\cdots+b k x k i$

where $y$ is the observed response(mass transfer coefficient $\mathrm{cm} / \mathrm{hr}$ ) to the values $x 1 i, x 2 i, \ldots, x k i$ of the $k$ independent variables $x 1, x 2, \ldots, x k$. Three factor (X1 temp. ,X2 time and X3 PH of solution), i number of level (three level for $\mathrm{X} 1$ and $\mathrm{X} 2\left(35 \mathrm{c}^{\mathrm{o}}, 37 \mathrm{c}^{\mathrm{o}}, 39 \mathrm{c}^{\mathrm{o}}, 1 \mathrm{hr}, 3 \mathrm{hr}\right.$ and $5 \mathrm{hr}$ )sequentially and two level for X3(1.5 and 6.5).

Figs. 8 and 9 shows the main effect plot. There is no significant effect, if the line was horizontal in the sense that the effect of all levels of factors on response value was in the same way, and the average of response was the same in all levels of factors .there is a significant effect, if the line was not horizontal in the sense that the effect of the levels was different from one factor to another. The larger the variety of plots in the vertical axis, in other words the drawn points were not parallel to the $\mathrm{X}$-axis, the greater the value of the main effect. The relative quantity of effect of factors can be compared by comparing slope lines. 
Table 2. Result of statistical analysis for mass transfer coefficient

study

\begin{tabular}{|c|c|c|c|c|c|c|c|}
\hline complex & source & DF & Seq ss & contribution & F_value & P_value & R_sq \% \\
\hline \multirow{5}{*}{$\begin{array}{l}\text { naproxen/ } \\
\text { macro.AC }\end{array}$} & $\mathrm{PH}$ & 1 & 0.00 & $0.12 \%$ & $0 . \overline{3} 1$ & $0 . \overline{589}$ & \multirow{5}{*}{95.34} \\
\hline & TIME(hr) & 2 & 0.00 & $69.22 \%$ & 89.17 & 0.000 & \\
\hline & $\operatorname{TEM}\left(\mathrm{c}^{\mathrm{o}}\right)$ & 2 & 0.00 & $26.01 \%$ & 33.5 & 0.000 & \\
\hline & Error & 12 & 0.00 & $4.66 \%$ & ------ & ------ & \\
\hline & Total & 17 & 0.00 & $100 \%$ & ------ & ------ & \\
\hline \multirow{4}{*}{$\begin{array}{l}\text { naproxen/ } \\
\text { nano.AC }\end{array}$} & $\mathrm{PH}$ & 1 & 0.00 & $0.97 \%$ & 1.28 & 0.280 & \multirow{4}{*}{90.97} \\
\hline & TIME(hr) & 2 & 0.00 & $62.78 \%$ & 41.7 & 0.000 & \\
\hline & Error & 12 & 0.00 & $9.03 \%$ & ------ & ------ & \\
\hline & Total & 17 & 0.00 & $100 \%$ & ------ & ------ & \\
\hline
\end{tabular}

Table 3. Regression Equations

\begin{tabular}{ll}
\hline Samples & Regression equations \\
\hline naproxen/ & $\mathrm{y}=0.000193-0.000053 \mathrm{X} 11+0.000080 \mathrm{X} 12$ \\
macro.AC & $-0.000028 \mathrm{X} 13+0.000131 \mathrm{X} 21-0.000046 \mathrm{X} 22$ \\
& $\mathrm{y}=0.000090-0.000006 \mathrm{X} 11+0.000034 \mathrm{X} 12$ \\
naproxen/ & $-0.000028 \mathrm{X} 13+0.000053 \mathrm{X} 21-0.000016 \mathrm{X} 22$ \\
nano.AC & $-0.000037 \mathrm{X} 23-0.000005 \mathrm{X} 31+0.000005 \mathrm{X} 32$ \\
\hline
\end{tabular}

Figs. 10 and 11 show the residuals plot. The residuals versus fits plot, which has the independent variable on the horizontal $(\mathrm{X})$ axis and the remains on the vertical $(\mathrm{Y})$ axis. This plot explains a fairly irregular pattern all residual points above the line are positive, the points down are negative. This irregular pattern refers that a linear model gives the data a decent fit, and indicating a good fit for a linear model.

Residuals against order plot show the residues values in the vertical axis versus the order of experiments sequence in which the data were collected. It was used to find out whether the residues values were independent of each other from one experiment to another. The remains were randomly located around the midline patterns, where dots were close together which may be indicated that these may be not independent values [21].

Residuals plot histogram shows whether the residuals values are normally distributed, i.e., to determine whether the data is skewed or contains outliers. Asymmetric graph around zero in the form of a bell meaning that points are distributed evenly around zero which indicates that the assumption of normal state is likely to be correct. A long tail in one direction indicates deviation, and the tape that was away from the other bars may point to an outlier. Extreme tops can describe as extremely low or too high values that are not near any other data points [22].

The plot of normal probability for a residual showed the residuals in $\mathrm{X}$-axis versus expected values for their in $\mathrm{Y}$-axis. Whenever the distribution of points around the line was regular (The plot nearly follows an alignment line), this indicates that the equations represent the system more precisely and verify the assumption of distributed normally to the residuals, little points Located far from the line means an outliers distribution [23]

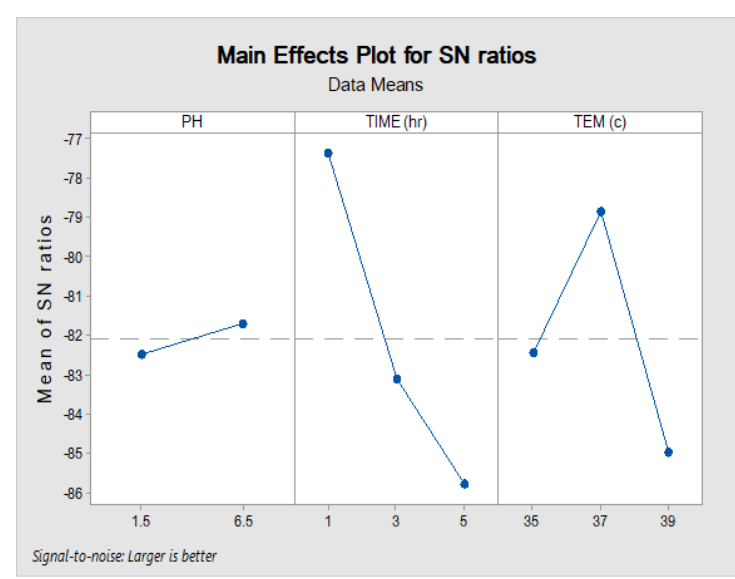

Figure 8. Main effects plot for signal to noise ratio naproxen/macro $\mathrm{AC}$ complex

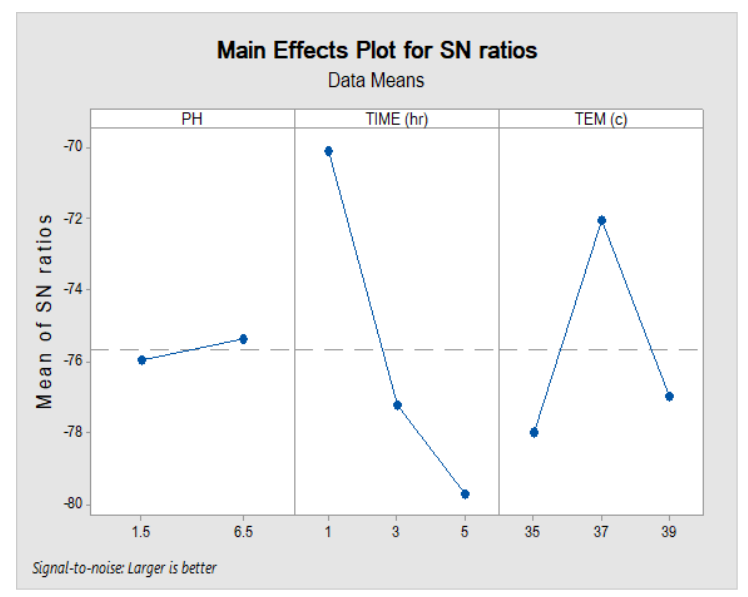

Figure 9. Main effects plot for signal to noise ratio naproxen/Nano AC complex 


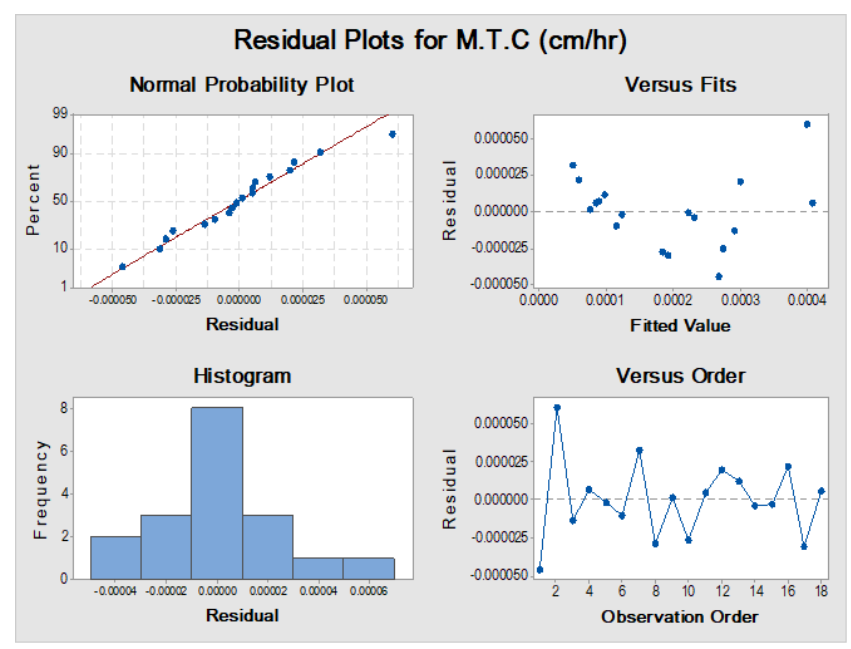

Figure 10. Residual plots for naproxen /macro. AC complex

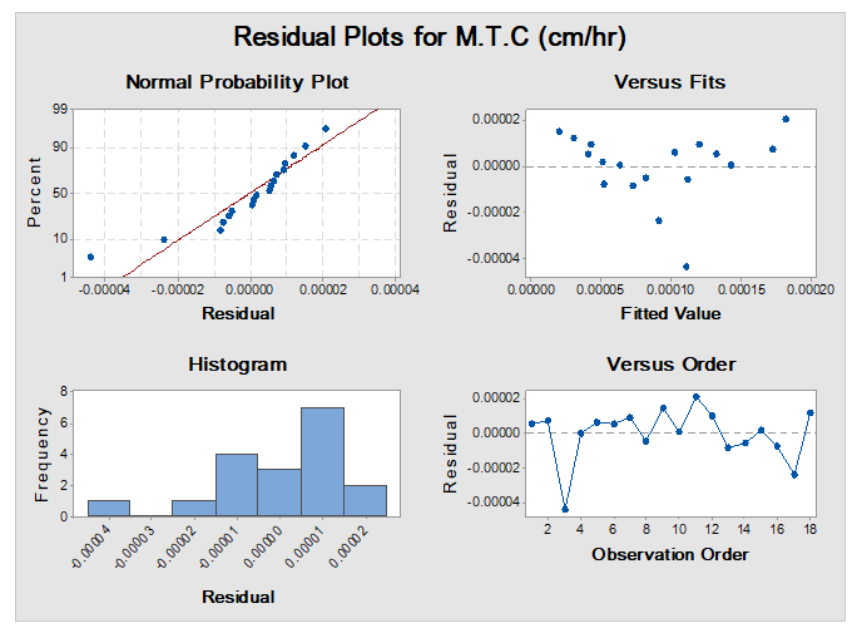

Figure 11. Residual plots for naproxen /Nano AC complex

\section{Conclusions}

Loading of naproxen was successfully achieved in activated carbon pores. The maximum loading efficiency for the drug was $59 \%$ when the activated carbon molecular in nanoparticle size and when the weight ratio of drug to activated carbon more than 1. Furthermore, the mass transfer in the drug delivery process was more controlled when the activated carbon was in nanoparticle size.

The best temperature given the maximum mass transfer coefficient was $37^{\circ} \mathrm{C}$, and this corresponds to the heat of the human body. Also the difference in $\mathrm{pH}$ of solution values was no strong effected on release drugs this is because all the solutions used were acidic corresponds to the middle of the stomach and intestines of the human.

\section{REFERENCES}

[1] Rossi, F., Perale, G. and Masi, M., Controlled drug delivery systems: towards new frontiers in patient care. Springer International Publishing, (2016).
[2] Sengupta, A. Intracellular drug delivery using laser activated carbon nanoparticles (Doctoral dissertation, Georgia Institute of Technology), (2014).

[3] S. ChatterjeeFDA Perspective on Continuous Manufacturing, IFPAC Annu. Meet. , (2012).

[4] M. Krumme, Control strategies for continuous processes, talk at 10th World Meeting on Pharmaceutics, Biopharmaceutics and Pharmaceutical Technology, Glasgow (UK), (2016) April 7th.

[5] Kushwaha, S.K.S., Ghoshal, S., Rai, A.K. and Singh, S. Carbon nanotubes as a novel drug delivery system for anticancer therapy: a review. Brazilian Journal of Pharmaceutical Sciences, 49(4), (2013)pp.629-643.

[6] Dạ browski, A.,Adsorption - From theory to practice. Advances in Colloid and Interface Science, 93(1-3), (2001) pp.135-224.

[7] Newcombe, G. Chapter Twentysix - Adsorption from Aqueous Solutions: Water Purification. In E. J. Bottani \& J. M. D. Tascón, eds. Adsorption by Carbons. Amsterdam: Elsevier, (2008)pp. 679-709.

[8] Truskey GA, Yuan F, Katz DF., Transport Phenomena in Biological Systems. Upper Saddle River, New Jersey:Pearson Education,Inc( 2004).

[9] Foy BD and Blake J. Diffusion of Paramagnetically Labeled Proteins in Cartilage: Enhancement of the 1-D NMR Imaging Technique. Journal of Magnetic Resonance Imaging ; (2001),148:126-34.

[10] Banker, G.S., Siepmann, J. and Rhodes, C., Modern Pharmaceutics, Fourth Edition, CRC Press, (2012).

[11] Leuner, C. and Dressman, J. Improving drug solubility for oral delivery using solid dispersions. European journal of pharmaceutics and biopharmaceutics : official journal of Arbeitsgemeinschaft für Pharmazeutische Verfahrenstechnik e.V, 50(1), (2000), pp.47-60.

[12] Limnell, T., Surface chemistry and pore size affect carrier properties of mesoporous silicon microparticles. International Journal of Pharmaceutics, 343(1-2), (2007). pp.141-147.

[13] Smith, B.T., Physical pharmacy Remington., Pharmaceutical Press(2016).

[14] Salonen, J.,Mesoporous silicon in drug delivery applications. Journal of Pharmaceutical Sciences, 97(2), (2008),pp.632-653.

[15] Miriyala, N., Ouyang, D., Perrie, Y., Lowry, D. and Kirby, D.J. Activated carbon as a carrier for amorphous drug delivery: Effect of drug characteristics and carrier wettability. European Journal of Pharmaceutics and Biopharmaceutics, 115, (2017) pp.197-205.

[16] Snyder, S.A., Adham, S., Redding, A.M., Cannon, F.S., DeCarolis, J., Oppenheimer, J., et al. Role of membranes and activated carbon in the removal of endocrine disruptors and pharmaceuticals. Desalination,(2007). 202, 156-181.

[17] Marsh, H., Reinoso, F.R. activated carbon Elsevier, (2006).

[18] Kim, S.D., Cho, J., Kim, I.S., Vanderford, B.J., Snyder, S.A. Occurrence and removal of pharmaceuticals and endocrine disruptors in South Korean surface, drinking, and waste waters. Water research. : (2007), 41, 1013-1021

[19] Salonen, J., Laitinen, L., Kaukonen, A.M., Tuura, J., Björkqvist, M., Heikkilä, T., Vähä-Heikkilä, K., Hirvonen, J. and Lehto, V.P. Mesoporous silicon microparticles for oral drug delivery: loading and release of five model drugs. Journal of controlled release, 108(2-3), ., (2005),pp.362-374.

[20] Ghoshal, S., Kushwaha, S.K.S., Srivastava, M. and Tiwari, P.,Drug loading and release from functionalized multiwalled carbon nanotubes loaded with 6-mercaptopurine using incipient wetness impregnation method. Am J Adv Drug Del, 2(2), (2014),pp.213-223.

[21] Ranganath, M. S., Mishra RS Vipin, and Nikhil Prateek. "Optimization of Surface Roughness in CNC Turning of Aluminium 6061 Using Taguchi techniques." International Journal of Modern Engineering Research 5 (2015): 42-50.

[22] Bhattacharya, Anirban, Santanu Das, P. Majumder, and Ajay Batish. "Estimating the effect of cutting parameters on surface finish and power consumption during high speed machining of AISI 1045 steel using Taguchi design and ANOVA." Production Engineering 3, no. 1 (2009): 31-40.

[23] Olabi, A. G., G. Casalino, K. Y. Benyounis, and M. S. J. Hashmi. "An ANN and Taguchi algorithms integrated approach to the optimization of CO2 laser welding." Advances in Engineering Software 37, no. 10 (2006): 643-648. 